\title{
Transcriptomic Fingerprint of Bacterial Infection in Lower Extremity Ulcers
}

Blaine Fritz ${ }^{1}$, Julius Bier-Kirkegaard ${ }^{2}$, Claus Henrik Nielsen ${ }^{3}$, Klaus Kirketerp-Møller ${ }^{4}$, Matthew Malone ${ }^{5,6}$, Thomas Bjarnsholt ${ }^{1,7}$

1. Department of Immunology and Microbiology, Faculty of Health and Medical

Science, University of Copenhagen, Copenhagen, Denmark

2. Niels Bohr Institute, University of Copenhagen, Copenhagen, Denmark

3. Department of Rheumatology and Spine Diseases, Institute for Inflammation

Research, Rigshospitalet, Copenhagen, Denmark

4. Center for Wound Healing, Bispebjerg Hospital, Copenhagen, Denmark

5. South West Sydney Limb Preservation and Wound Research, Liverpool Hospital, Sydney, Australia

6. Infectious Diseases and Microbiology, School of Medicine, Western Sydney University, Sydney, Australia

7. Department of Clinical Microbiology, Rigshospitalet, Copenhagen, Denmark

Classification: Biological Sciences; Immunology and Inflammation

Keywords: diabetic foot, ulcer, chronic wounds, transcriptomics, RNA sequencing, biofilm, infection, machine learning

Corresponding Author: Thomas Bjarnsholt (tbjarnsholt@sund.ku.dk) 
medRxiv preprint doi: https://doi.org/10.1101/2021.12.20.21267962; this version posted December 25, 2021. The copyright holder for this

\section{Abstract}

Clinicians and researchers utilize subjective classification systems based on clinical parameters to stratify lower extremity ulcer infections for treatment and research. This study compared clinical infection classifications (mild to severe) of lower extremity ulcers $(n=44)$ with transcriptomic profiles and direct measurement of bacterial RNA signatures by RNAsequencing. Samples demonstrating similar transcriptomes were clustered and characterized by transcriptomic fingerprint. Clinical infection severity did not explain the major sources of variability among the samples and samples with the same clinical classification demonstrated high inter-sample variability. High proportions of bacterial RNA, however, resulted in a strong effect on transcription and increased expression of genes associated with immune response and inflammation. K-means clustering identified two clusters of samples, one of which contained all of the samples with high levels of bacterial RNA. A support vector classifier identified a fingerprint of 20 genes, including immune-associated genes such as CXCL8, GADD45B, and HILPDA, which accurately identified samples with signs of infection via cross-validation. This suggests that stratification of infection states based on a transcriptomic fingerprint may be a useful tool for studying host-bacterial interactions in these ulcers, as well as an objective classification method to identify the severity of infection. 
medRxiv preprint doi: https://doi.org/10.1101/2021.12.20.21267962; this version posted December 25, 2021. The copyright holder for this

\section{Significance Statement}

Clinicians and researchers utilize classification schemes based on clinically measurable parameters to describe infection severity in lower extremity ulcers. However, here we show that the local host gene expression is often discordant to clinical classification scores. We observed this inconsistency is explained by the increased presence of bacteria, which promotes increased immune and inflammatory responses. Two groups of host gene expression, predominantly differentiated by the levels of bacterial RNA, could be classified with less than 20 genes. These results provide significant insights into host response to bacterial infection where bacteria are directly observed, rather than implied from clinical observation, and illustrated the limitations of clinical observations to stratify lower extremity ulcers. 
medRxiv preprint doi: https://doi.org/10.1101/2021.12.20.21267962; this version posted December 25, 2021. The copyright holder for this

\section{Introduction}

Lower extremity ulcers present both humanistic and economic burdens to society. A UK study identified a prevalence of chronic lower extremity wounds in $6 \%$ of the population with management costs amounting to $£ 328.8$ million[1]. One type of lower extremity ulcer with high burden are diabetic-related foot ulcers (DFU). DFUs arise due to compromised arterial circulation, peripheral neuropathy, and repeated injury. Many individuals also demonstrate dysregulation of the immune response and poor glycemic control. The combination of these complex comorbitities likely increases the potential of DFUs to develop infection and osteomyelitis [2, 3]. More than 50\% of DFUs will become infected [4], which increases the likelihood of poor clinical outcomes, risk of hospital admission, and lower extremity amputation $[5,6]$. DFUs may take weeks, months, or years to heal and $65 \%$ of patients develop a new ulcer within 5 years $[3,7]$. These cycles of re-ulceration and/or infection contribute to reduced quality of life, increased morbidity and mortality. Similarly, persons with leg ulcers can experience prolonged pain, social challenges, and decreased psychological well-being [6, 8-10].

Several classification systems exist for the stratification of DFUs and grading of infection severity. These include the Infectious Diseases Society of America/International Working Group on the Diabetic Foot (IDSA/IWGDF) guidelines [11], Wagner classification system [12], University of Texas system (UT) [13], site/ischaemia/neuropathy/bacterial infection/depth (SINBAD) system [14], diabetic ulcer severity score (DUSS) [15], and perfusion/extent/depth/infection/sensation (PEDIS) systems [16]. These classifications combine clinical data and observations to stratify wounds, classify infections, guide treatment, and predict outcomes [17]. A limitation of classification systems is that clinical observations are open to 
medRxiv preprint doi: https://doi.org/10.1101/2021.12.20.21267962; this version posted December 25, 2021. The copyright holder for this

observer interpretation and may vary greatly, depending on the observer and/or the patient's physiological state[18]. Underlying comorbidities such as diabetes mellitus or peripheral arterial disease further compound the clinical picture and have been implicated as causes of immune dysfunction and/or reduced infection symptoms [19, 20].

Recent advances in RNA sequencing technologies have allowed high-resolution examination of gene-expression of ulcer tissue and infecting bacteria at the bulk and single-cell level. For example, stratification by infection severity demonstrated increased microbial diversity as well as a unique host-response in severe DFIs [21, 22]. Wound healing has also been studied as an important outcome. Dysregulation of major transcriptional networks, such as those associated with migration of neutrophils and macrophages and inflammation have been identified in nonhealing wounds $[23,24]$. Unique subpopulations of fibroblasts have also been linked to improved wound healing [23]. Furthermore, transcriptomic studies have identified unique transcriptome of bacteria during chronic infection [25]. Studies examining transcription as a factor of infection severity often utilize clinical scores to classify highly infected samples, though there is evidence that clinical infection scores do not correspond with bacterial load [18].

In this study, we analyzed RNA sequencing data of clinically infected DFU biopsies to examine the effect of bacterial load on host transcription and correlation to clinical parameters. We assessed both the clinical infection severity score (IDSA) as well as direct measurement of bacterial activity in the samples to explain changes in the host transcriptome. We then identify differentially expressed genes and pathways which are characteristic for DFUs demonstrating 
medRxiv preprint doi: https://doi.org/10.1101/2021.12.20.21267962; this version posted December 25, 2021. The copyright holder for this

signs of bacterial infection. From these genes, we develop a transcriptomic fingerprint of $\sim 20$ genes, which could be utilized to identify infected DFUs and guide treatment.

\section{Methods}

\section{Sample collection and external data sources}

Tissue biopsies were collected from either the Liverpool Hospital (LHS) High-Risk Foot Service, Liverpool Hospital, Liverpool, Australia. External RNA-sequencing data utilized for the fingerprint validation was obtained from Heravi et al[22]. LHS samples were collected from patients presenting with an infected foot ulcer, where a punch-biopsy was taken postdebridement. Detailed tissue collection methods are described in Supplementary Information (SI). All tissue samples were immediately placed into RNAlater, incubated at $4{ }^{\circ} \mathrm{C}$ for 24 hours, and then frozen at $-80^{\circ} \mathrm{C}$ until RNA extraction. The clinical metadata categories of interest were ulcer duration $(0=$ less than 2 weeks, $1=2$ to 4 weeks, $2=$ greater than 4 weeks $)$, PEDIS/IDSA infection score $(2=$ mild, $3=$ moderate, $4=$ severe $)[38]$.

\section{RNA extraction, library preparation, and sequencing}

Frozen samples in RNAlater were thawed on ice. The tissue was removed and placed inside an empty, sterile Petri plate. A scalpel was used to cut a piece of tissue with a volume of approximately $0.5 \mathrm{~cm}^{3}$. RNA extraction was then performed chloroform/phenol phase separation, as previously described $[25,39]$ with some modifications. The tissue was placed in a $2 \mathrm{~mL}$ microtube (Sarstedt, Germany, Cat: 72.693.005) filled one-third with $2 \mathrm{~mm}$ and $0.1 \mathrm{~mm}$ diameter zirconia beads (Biospec, USA). One milliliter of RNABee (Amsbio, UK, cat: CS-501) containing $10 \mu \mathrm{L} / \mathrm{mL} \beta$-mercaptoethanol was added to the tubes. The tubes were placed in a MagNA Lyzer instrument (Roche) and homogenized at maximum power for 3 x 30 seconds. Tubes were placed on ice for $1 \mathrm{~min}$ after each homogenization step. The tubes were shaken 
medRxiv preprint doi: https://doi.org/10.1101/2021.12.20.21267962; this version posted December 25, 2021. The copyright holder for this

vigorously for $30 \mathrm{sec}$, incubated for $5 \mathrm{~min}$ on ice, and then centrifuged at 13,000 x g for $30 \mathrm{~min}$ at $4{ }^{\circ} \mathrm{C}$. The upper aqueous phase was collected and placed in a new, $1.5 \mu \mathrm{L}$ DNA Lo-Bind ${ }^{\circledR}$ centrifuge tubes (Eppendorf AG, Germany, cat: 0030108051). Ice-cold ethanol (0.5mL) and $2 \mu 1$ of $5 \mathrm{mg} / \mathrm{mL}$ linear acrylamide was added. The tubes were inverted several times and stored at $80{ }^{\circ} \mathrm{C}$ overnight. The samples were then thawed on ice and centrifuged $(13,000 \mathrm{x} \mathrm{g}, 30 \mathrm{~min},+4$ $\left.{ }^{\circ} \mathrm{C}\right)$. The supernatant was discarded and the pellet was washed twice with fresh, ice-cold $75 \%$ ethanol. The pellet was then resuspended in $20-65 \mu \mathrm{L}$ nuclease free water. RNA concentration was quantified with a NanoDrop spectrophotometer. Contaminating DNA was removed by combining $\sim 2.5 \mu \mathrm{g}$ RNA with $3 \mu \mathrm{L}$ RQ-1 RNAse Free DNase (Promega, USA), $3 \mu \mathrm{L}$ DNAse buffer solution, $1 \mu \mathrm{L}$ RiboGuard ${ }^{\mathrm{TM}}$ RNAse inhibitor (Lucigen, USA, cat: RG90925), and nuclease free water to a final volume of $30 \mu \mathrm{L}$. The DNAse-treated RNA was then re-purified with the RNABee protocol described above and then stored at $-80^{\circ} \mathrm{C}$. Ribosomal RNA depletion was performed either with the 10:1 human:pan-prokaryote riboPOOLs (siTOOLS Biotech, Germany, protocol version: 1.4.2). The NEBNext ${ }^{\circledR}$ Ultra II RNA library preparation kit (New England Biolabs (NEB), USA, cat: E7775S) was used to prepare cDNA libraries for the LHS samples. Concentrations and quality of the final libraries were assessed with a Qubit 4 fluorometer and Agilent Bioanalyzer. Samples were sequenced either on an Illumina HiSeq4000 or Novaseq sequencing instrument.

\section{QC processing, alignment, quantification, and bias control of sequence data}

All raw sequence data, including external data, was processed at the same time, using the same pipeline, though accounting for paired-end or single-end data. Adapter and quality trimming was performed with cutadapt 2.4 [40]. Reads less than 20 nucleotides after trimming were discarded. 
medRxiv preprint doi: https://doi.org/10.1101/2021.12.20.21267962; this version posted December 25, 2021. The copyright holder for this

In-silico rRNA depletion was performed with SortMeRNA v 2.1 against the SILVA rRNA database to remove eukaryotic, bacterial, or archaeal ribosomal sequences. The reads were then aligned with bwa-mem with default settings (v. 0.7.16a) against the GRCh38 human genome assembly (GCA_000001405.15, RefSeq, full analysis set), including all alternative haplotypes and unlocalized scaffolds. Aligned reads were then assigned to exon features in the using the NCBI RefSeq annotation with featureCounts [41]. Any samples containing less than 1 million reads then discarded from the analysis. Any exonic features which represented other transcript types, such as ncRNA and tRNA, were also removed from the analysis. To normalize for batch differences between data sets, differential gene expression was performed between LHS data and the external data from Heravi et al [22]. Any genes identified as differentially expressed in this analysis were removed from the data set. This data was then used for further analysis.

\section{Principal component analysis, k-means clustering, and differential gene-expression}

The raw count data was normalized using DESeq2's variance stabilizing transformation (vst, blind $=$ TRUE, nsub $=1000$ ) and analyzed with the prcomp function in $\mathrm{R}$ with no additional scaling. The first two principal components were plotted (Figure 1). Component loading analysis and principal component correlations were performed with the R package, PCAtools. Spearman correlation with benjamini Hochberg correction for multiple comparisons was used for the correlation analysis of metadata with principal component positioning. The optimal number of clusters for k-means was selected by the fviz_nbclust function the factoextra package (v. 1.0.7) using the "silhouette" method. Differential gene expression analysis was performed with DEseq2 (v. 1.28.1), using default settings. Samples missing data in any of these metadata categories included in the models were removed from the dataset before the analysis. To identify differentially expressed genes due to clinical parameters, the IDSA/PEDIS score, categorical 
medRxiv preprint doi: https://doi.org/10.1101/2021.12.20.21267962; this version posted December 25, 2021. The copyright holder for this

ulcer duration and a binary variable for if the sample contained $>10$ percent bacterial reads was used for DEeq2 model formula. To identify differentially expressed genes due to k-means cluster, the only variable in the formula was k-means cluster. In all cases, genes with an adjusted p-value of $<0.05$ and an absolute $\log 2$ fold-change $>2$ were considered significantly differentially expressed.

Functional characterization of the groups identified by k-means clustering was performed using PANTHER[42], using fisher's exact test and false-discovery rate FDR $<0.05$. Significantly differentially expressed genes with a positive $\log 2$ fold-change for a given comparison were used as the input and the list of all genes used as input to the differential gene expression analysis was used as the reference list. The annotations list used was the "GO biological process complete" data set (GO Ontology database DOI: 10.5281/zenodo.4081749, Released 2020-10-09).

\section{Feature Selection and Testing}

To identify gene features that could be used to identify specific levels of clinical metadata or clusters of samples, a support vector machine (SVM) with a linear kernel with was fitted to the normalized data for PEDIS/IDSA score and k-means cluster. The most important features in the model were then selected based on the SVM coefficients to select for features for classification.

To evaluate the optimal number of features to include in the model, this process was repeated for up to 100 features. For each number of features (1-100), the given number of features was selected and a stratified 6-fold cross validation was performed. Twenty genes were selected by the authors as the optimal number to avoid overfitting and account for additional variability when using external data. All analyses were performed with the python library scikit-learn (v. 1.0) [43]. 
medRxiv preprint doi: https://doi.org/10.1101/2021.12.20.21267962; this version posted December 25, 2021. The copyright holder for this

\section{Results}

RNA-sequencing was performed on thirty DFUr biopsies obtained from Liverpool Hospital, Liverpool Australia (samples annotated as P500-P529). Raw RNA sequence data $(\mathrm{n}=14)$ from [22] was also included in the data set (samples prefixed with $\mathrm{HH}^{*}$ ). The combined data set yielded an average of $153 \pm 23.9 \mathrm{M}$ reads per sample passing quality filters. Samples from the Liverpool data showed significantly more rRNA contamination than the HH data with mean percentages of rRNA contamination of $57.4 \pm 17$ and $5.0 \pm 1$, respectively. The non-rRNA reads were then aligned to the human reference genome and all reads mapping to exonic gene features were counted. Samples with less than 1M reads were excluded. Additionally, sample HH5 was excluded, as it was an extreme outlier. To control for variability due to source, differential gene expression analysis was performed, and 14,210 genes identified as differentially expressed were removed from the analysis, leaving 32,841 genes, which were analyzed (unless otherwise noted). The final data set contained a mean and median of $26.7 \pm 21 \mathrm{M}$ and $20.9 \mathrm{M}$ reads per sample, respectively.

Presence of bacteria is associated with shift in host transcriptome

To evaluate the effect of bacteria on the host transcriptome, the data was first normalized and summarized with principal component analysis (PCA). The results of the PCA analysis are plotted in Figure 1. The first two principal components summarized $49.1 \%$ of the overall variability. We observed that the majority of samples clustered positively along the first principal component (PC1), while a subset of samples was spread across PC1 in the negative direction. 
medRxiv preprint doi: https://doi.org/10.1101/2021.12.20.21267962; this version posted December 25, 2021. The copyright holder for this

The samples were evenly distributed along PC2. To determine which factors affected this positioning, we tested whether clinical metadata variables or percentage of bacterial reads in the samples correlated with any of the first 10 principal components. The proportion of bacteria/human reads was the factor showing significant correlation along either PC1 and PC2 $\left(\mathrm{r}^{2}\right.$ $=0.29, \mathrm{p}<0.05$, spearman correlation with benjamini-hochberg correction). Levels of C-reactive protein as well as infection classification score showed slightly significant correlation to PC4, but this represented only a small proportion of the overall variability in the data. Additionally, the effect of increased proportions of bacterial reads was more prominent than batch variability between sources prior to correction of batch effects (Figure 1C, Supplementary Figure 1).

To further demonstrate that the positioning represented biological effects of bacteria rather than confounding factors, such as decreased sequencing depth of the host due to the high presence of bacteria, we examined which genes drive the variation across each principal component. Of the top $5 \%$ most weighted genes, the genes with the strongest loading in the negative directions included inflammatory cytokines (CXCL8, CXCL5, IL6, IL1), keratinocyte factors associated with bacterial infection $(K R T 6 A)$ and a matrix metalloprotease induced under inflammation $(M M P 1)$. The genes with the strongest positive loading across included collagens associated with extracellular matrix deposition (COL14A1, COL3A1, COL1A2), actin-binding (SYNPO2), apoptosis (SFRP4), alcohol metabolization $(A D H 1 B)$, complement $(C 7)$, and cellular gap junctions (GJB2). This suggested that shift in positioning across $\mathrm{PC} 1$ in the negative direction is due to increased expression of immune-related genes, likely in response to bacterial infection.

Enrichment of Immune Processes and Inflammation in Samples with High Bacterial Activity 
medRxiv preprint doi: https://doi.org/10.1101/2021.12.20.21267962; this version posted December 25, 2021. The copyright holder for this

To confirm that samples with increased bacterial activity represented a specific transcriptomic response and to generate groups for comparative analysis, we performed k-means clustering on the normalized expression data. This analysis identified two cluster of samples, C1 $(n=8)$ and C2 $(n=36)$ (Figure 2a). The mean proportion of bacterial:human reads per sample was significantly higher in $\mathrm{C} 2(\mathrm{t}=4.0367$, p-value $=0.005$, Welch $\mathrm{t}$-test; Figure $2 \mathrm{C})$. We then tested for genes that showed differential expression between these two clusters using DESeq2. This analysis identified 2793 genes differentially expressed ( $\mid \log 2$ FoldChange $\mid>2$, adjusted p-value <0.05) between these two groups. Of these, 251 and 2541 genes showed significantly increased expression in $\mathrm{C} 1$ and $\mathrm{C} 2$, respectively. In comparison, the same analysis identified only identified 114 genes differentially expressed between different levels of ulcer severity, likely due to high variability among samples with the same clinical classification.

C1 demonstrated increased expression of the cytokines (CXCL12, CXCL13) and cadherins (CD34, CD36). C2 demonstrated increased expression of S100A8/9 and S100A12. ADAM8 showed significantly increased expression in C2. In C2, we identified significantly increased expression of several leukocyte-associated cytokines (CXCL8,CXCL2, CXCL16, IL6, etc) and cadherins (CD53, CD69). We also observed increased expression of NFKB2, but also relatively higher expression NFKB inhibitors (NFKBIA, NFKBIZ). Though differentially expressed in C2, expression of TNF-alpha was low.

To examine whether the genes differentially expressed between the $\mathrm{C} 1$ (low bacterial activity) and C2 (high bacterial activity) represented enrichment of known biological processes, we performed a Gene Ontology enrichment analysis using PANTHER (Figure 2b). In the cluster with high bacterial activity (C2), we identified enrichment of 28 pathways $(\mathrm{FDR}<0.05)$, including the specific subclasses, "cellular response to lipopolysaccharide" (GO: 0071222), 
medRxiv preprint doi: https://doi.org/10.1101/2021.12.20.21267962; this version posted December 25, 2021. The copyright holder for this

"immune response-regulating signaling pathway" (GO:0002764), "inflammatory response" (GO: 0006954), and "innate immune response" (GO: 0045087). In C1, there were 15 significantly enriched pathways (FDR $<0.05)$, including "collagen fibril organization" (GO:0030199), “collagen metabolic process" (GO:0032963), “complement activation” (GO:0006956), “cell-matrix adhesion” (GO:0007160).

\section{Differential host response to Staphylococcus aureus}

To investigate which bacterial species were present and active in the samples, KRAKEN was used to identify reads originating from bacteria and assign taxonomy (Figure $2 \mathrm{~d}$ ). In four of the six samples with high bacterial signals, at least $50 \%$ of the reads classified to bacteria were identified to a single species (S. aureus, S. epidermidis, Proteus mirabilis, or Porphyromonas asaccharolytica). We hypothesized that samples with increased signals of infection (i.e. C2) would display decreased alpha diversity. There was, however, no significant different in the number of species between the clusters $(t=-0.071, p=0.94$, Welch $t$-test $)$ for species with a minimum of $5 \%$ bacterial reads. We further investigated whether Staphylococcus aureus, which was highly active in two samples with increased signals of infection (C2) was also present in other samples with lower signals of infection (i.e. C1). Interestingly, S. aureus, was also found in 13 samples with low signs of infection (C1). This demonstrates a difference in host response between wounds, despite the presence of the same pathogenic bacterial species.

\section{Definition and validation of transcriptomic fingerprint to classify ulcer status}

To identify a small set of genes, which could be used to identify samples with a bacterial infection, a support vector classifier (SVC) was applied to the RNA-seq data to select a reduced 
medRxiv preprint doi: https://doi.org/10.1101/2021.12.20.21267962; this version posted December 25, 2021. The copyright holder for this

set of gene-features to define each cluster. Results of this analysis are displayed in Figure 3. Twenty gene-features were selected, which were selected from the model as useful classifiers to differentiate between samples in $\mathrm{C} 1$ and $\mathrm{C} 2$ (Figure 3a,b). We evaluated the accuracy of the classifier when trained with between 1 and 100 features and obtained high accuracy with less than 10 genes, but conservatively included 20 genes to increase the robustness of the model (Figure 3d). Several of the identified genes were associated with immune cells and inflammation, including CXCL8 (neutrophil recruitment [26]), GADD45B (stress-response[27]), HILPDA (macrophage infiltration [28]), and KIF21B (T-cell polarization [29]). The normalized expression of these genes was also clearly elevated in $\mathrm{C} 2$ relative to $\mathrm{C} 1$ (Figure 3e). Genes that were negative classifiers for C2 (i.e. demonstrated increased expression in C1) included metalloproteases $M M P 10$ and MMP12, the collagen matrix protein COL1A2, and the chemokine CCL21. The feature with the largest coefficient was SLCO2A1, which showed increased expression in $\mathrm{C} 1$.

We additionally performed the same analysis on the PEDIS/IDSA score to evaluate whether the model based on the clusters would perform to classify infection in samples compared to a model based on the clinical PEDIS/IDSA infection score classification system (Supplementary Figure 2,3). For the clinical PEDIS/IDSA, the model only achieved a maximum of $75-80 \%$ accuracy for predicting the PEDIS/IDSA score of the testing data with $\sim 30$ genes (Supplementary Figure 4). This was also to be expected, as there did not appear to be a difference in gene expression for the features selected as good classifiers for PEDIS/IDSA score.

\section{Discussion}

This study examined clinically infected DFUs to investigate whether clinical infection classification or ulcer duration reflect ulcers' gene expression profiles, determined by RNA- 
medRxiv preprint doi: https://doi.org/10.1101/2021.12.20.21267962; this version posted December 25, 2021. The copyright holder for this

sequencing. We observed that most of the variability in the data was not described by infection severity classification or ulcer duration. Rather, that the proportion of bacterial reads was a driving force in transcriptomic variation. Unsupervised clustering identified two groups of samples in the data, where one group demonstrated significantly increased bacterial activity. These groups were inconsistent with an ulcer's infection classification and duration, despite the samples clustering in the same cluster. Samples with increased proportions of bacteria exhibited increased expression of genes associated with immune cells and inflammation, suggesting a direct response to the bacterial threat. We then identified a fingerprint of 20 genes, including molecules of the immune system such as CXCL8, a chemoattractant for neutrophils [26], which accurately identified samples exhibiting a transcriptome consistent with high proportions of bacterial RNA.

Developing a robust system for the stratification of ulcers is essential for treatment and study. Several studies have performed comparisons between ulcers, based on stratification by clinical classification, but often do not account for the influence of bacterial activity on the local microenvironment [21, 30-33]. For example, a previous study of infected ulcers identified increased expression of $G A D D 45 B$, a DNA damage and stress response protein [27], (also identified in the present study) with IDSA/PEDIS scores of 4 [21].Our findings suggest rather that this gene and others are expressed only in a subset of samples with an IDSA/PEDIS score of 4, specifically those with high bacterial activity. Similarly, a previous study found no differences between microbiological data including presence of gram negative organisms or monomicrobial/polymicrobial infections among different grades of infection [33]. This is not to say that there is no difference in these parameters for severe infections, rather high variability 
medRxiv preprint doi: https://doi.org/10.1101/2021.12.20.21267962; this version posted December 25, 2021. The copyright holder for this

among samples with the same grade may lead to decreased statistical power to detect these differences.

Our results suggest an acute inflammatory response to bacteria in C2 relative to lower-level inflammation observed in C1. This is supported by the inclusion of CXCL8 and other molecules induced by an inflammatory environment in C2, such as BCL2 Related Protein A1 (BCL2A1), oncostatin $\mathrm{M}(O S M)$, prostaglandin $\mathrm{G} / \mathrm{H}$ synthase (PTSG2), and S-100 calcium binding protein A8/9 (S100A8/9). The increased expression of CXCL8 and ADAM8 also suggests active recruitment of neutrophils to the ulcer [34]. The presence of neutrophils in the samples is suggestd by the presence of hydroxycarboxylic acid receptor 2 (HCAR2) and oncostatin $\mathrm{M}$ $(O S M)$, which are produced by or present on neutrophils $[35,36]$. . In addition, the increased expression of interleukin-6 (IL6) in C2 supports the presence of pro-inflammatory, type 1 macrophages. Contrarily, the presence of a reduced immune response and inflammatory environment was suggested in $\mathrm{C} 1$. For example, CXC13, a selective chemoattractant for B cells [37], showed increased expression C1 suggesting the recruitment of B cells. Previous research has suggested that the inhibition of immune response and recruitment of immune cells may lead to decreased wound healing, suggesting that $\mathrm{C} 1$ may represent a chronic-like state in comparison to $\mathrm{C} 2$, where we observed genes associated with acute inflammatory response and recruitment of neutrophils.

This study and the interpretation of the findings presents several limitations. First, distribution of bacteria is known to be heterogeneous within diabetic foot ulcers, but the heterogeneity of gene expression in an ulcer has not been studied. Thus, it is unclear whether the difference between clusters arises from global difference in wound gene expression or sampling regions with or 
medRxiv preprint doi: https://doi.org/10.1101/2021.12.20.21267962; this version posted December 25, 2021. The copyright holder for this

without high levels of bacteria. We identified two samples in C2 with low bacterial activity, but yet clustered together with those exhibiting high bacterial activity, suggesting that the effect of bacteria may reach further than bacterias' physical presence. This also further demonstrated the heterogeneity of bacterial distribution within wounds.

In summary, we identified that increased bacterial activity is associated with an inflamed and neutrophilic host transcriptome in lower extremity ulcers. The presence of bacteria also explained differences in host transcriptomes, despite equivalent clinical classifications. We then presented a small subset of genes, with consistent differential expression in samples with signs of bacterial infection, which proved to be accurate for identifying unknown samples with probably bacterial infections. Classification of wound status based on expression of important indicator genes may provide a more representative of the true wound environment than subjective clinical observations and may aid clinicians in determining the best course of treatment. Future work will be to improve the classification and identify the most relevant genes for describing the states of the wound. Our data reveals the potential future application of RNA-seq in profiling the metatranscriptome of DFUs based on their biological/cellular function. This may reduce any ambiguity of classifying wounds based on clinical observations and advance a more personalized medicine approach to care.

\section{Code and Data Availability}

Raw sequence files for the RNA-seq data generated in this study are available at NCBI Sequence Read Archive (SRA) (Accession: PRJNA726011). The external data utilized in this analysis is available at NCBI SRA (Accession: PRJNA563930) [22]. Code to reproduce the analysis and 
medRxiv preprint doi: https://doi.org/10.1101/2021.12.20.21267962; this version posted December 25, 2021. The copyright holder for this

figures in the manuscript is available at www.github.com/costerton-biofilmcenter/WoundClassification2021.

\section{Ethics Statement}

Study ethics approval was granted by the South West Sydney Local Health District Research and Ethics Committee (HREC/14/LPOOL/487).

\section{Contributions and Acknowledgements}

$\mathrm{MM}, \mathrm{TB}$, and BF conceived and designed the project. MM collected and provided samples. BF Samples for this project were collected by MM. BF processed the samples. BF and JK performed the analysis. BF wrote the manuscript. BF, JK, CN, KK, MM, and TB read, revised, and edited the manuscript. Work for this project was supported by grants from The Lundbeck Foundation to TB and BF. TB is the guarantor of this work and, as such, had full access to all the data in the study and takes responsibility for the integrity of the data and the accuracy of the data analysis. We thank the GeoGenetics Sequencing Core at University of Copenhagen for assistance in generating the RNA-seq data and Computerome (www.computerome.dk) for providing the computing infrastructure to analyze the data. We thank Elio Rossi for useful discussions and contributions to the code used in the analysis. BF, JK, CN, KK, MM, and TB declare no conflicts of interest in relation to this work. 


\section{References}

1. Phillips, C.J., et al., Estimating the costs associated with the management of patients with chronic wounds using linked routine data. International Wound Journal, 2016. 13(6): p. 1193-1197.

2. Raffetto, J.D., et al., Why Venous Leg Ulcers Have Difficulty Healing: Overview on Pathophysiology, Clinical Consequences, and Treatment. J Clin Med, 2020. 10(1).

3. Armstrong, D.G., A.J.M. Boulton, and S.A. Bus, Diabetic Foot Ulcers and Their Recurrence. New England Journal of Medicine, 2017. 376(24): p. 2367-2375.

4. Prompers, L., et al., High prevalence of ischaemia, infection and serious comorbidity in patients with diabetic foot disease in Europe. Baseline results from the Eurodiale study. Diabetologia, 2007. 50(1): p. 18-25.

5. Skrepnek, G.H., et al., Health Care Service and Outcomes Among an Estimated 6.7 Million Ambulatory Care Diabetic Foot Cases in the U.S. Diabetes Care, 2017. 40(7): p. 936-942.

6. Herber, O.R., W. Schnepp, and M.A. Rieger, A systematic review on the impact of leg ulceration on patients' quality of life. Health and Quality of Life Outcomes, 2007. 5(1): p. 44.

7. Smith-Strom, H., et al., Severity and duration of diabetic foot ulcer (DFU) before seeking care as predictors of healing time: A retrospective cohort study. Plos One, 2017. 12(5). 
medRxiv preprint doi: https://doi.org/10.1101/2021.12.20.21267962; this version posted December 25, 2021. The copyright holder for this

8. Pedras, S., R. Carvalho, and M.G. Pereira, Predictors of quality of life in patients with diabetic foot ulcer: The role of anxiety, depression, and functionality. J Health Psychol, 2018. 23(11): p. 1488-1498.

9. Polikandrioti, M., et al., Quality of Life in Diabetic Foot Ulcer: Associated Factors and the Impact of Anxiety/Depression and Adherence to Self-Care. Int J Low Extrem Wounds, 2020.19(2): p. 165-179.

10. Zhao, H., et al., A Longitudinal Study on the Association Between Diabetic Foot Disease and Health-Related Quality of Life in Adults With Type 2 Diabetes. Can J Diabetes, 2020. 44(3): p. 280-286 e1.

11. Lipsky, B.A., et al., 2012 Infectious Diseases Society of America clinical practice guideline for the diagnosis and treatment of diabetic foot infections. Clin Infect Dis, 2012. 54(12): p. e132-73.

12. Wagner, F.W., Jr., The diabetic foot. Orthopedics, 1987. 10(1): p. 163-72.

13. Lavery, L.A., D.G. Armstrong, and L.B. Harkless, Classification of diabetic foot wounds. J Foot Ankle Surg, 1996. 35(6): p. 528-31.

14. Treece, K.A., et al., Validation of a system of foot ulcer classification in diabetes mellitus. Diabet Med, 2004. 21(9): p. 987-91.

15. Beckert, S., et al., A new wound-based severity score for diabetic foot ulcers: A prospective analysis of 1,000 patients. Diabetes Care, 2006. 29(5): p. 988-92.

16. Schaper, N.C., Diabetic foot ulcer classification system for research purposes: a progress report on criteria for including patients in research studies. Diabetes Metab Res Rev, 2004. 20 Suppl 1: p. S90-5. 
medRxiv preprint doi: https://doi.org/10.1101/2021.12.20.21267962; this version posted December 25, 2021. The copyright holder for this

17. Monteiro-Soares, M., et al., Diabetic foot ulcer classifications: A critical review. Diabetes-Metabolism Research and Reviews, 2020. 36.

18. Gardner, S.E., S.L. Hillis, and R.A. Frantz, Clinical signs of infection in diabetic foot ulcers with high microbial load. Biol Res Nurs, 2009. 11(2): p. 119-28.

19. Edmonds, M., Infection in the Neuroischemic Foot. The International Journal of Lower Extremity Wounds, 2005. 4(3): p. 145-153.

20. Lipsky, B.A., et al., Guidelines on the diagnosis and treatment of foot infection in persons with diabetes (IWGDF 2019 update). Diabetes Metab Res Rev, 2020. 36 Suppl 1: p. e3280.

21. Radzieta, M., et al., A multiomics approach to identify host-microbe alterations associated with infection severity in diabetic foot infections: a pilot study. npj Biofilms and Microbiomes, 2021. 7(1): p. 29.

22. Heravi, F.S., et al., Metatranscriptomic Analysis Reveals Active Bacterial Communities in Diabetic Foot Infections. Frontiers in Microbiology, 2020. 11(1688).

23. Theocharidis, G., et al., Integrated Skin Transcriptomics and Serum Multiplex Assays Reveal Novel Mechanisms of Wound Healing in Diabetic Foot Ulcers. Diabetes, 2020. 69(10): p. 2157-2169.

24. Sawaya, A.P., et al., Deregulated immune cell recruitment orchestrated by FOXM1 impairs human diabetic wound healing. Nature Communications, 2020. 11(1): p. 4678.

25. Cornforth, D.M., et al., Pseudomonas aeruginosa transcriptome during human infection. Proceedings of the National Academy of Sciences, 2018. 115(22): p. E5125-E5134.

26. Murphy, P.M., Neutrophil receptors for interleukin-8 and related CXC chemokines. Semin Hematol, 1997. 34(4): p. 311-8. 
medRxiv preprint doi: https://doi.org/10.1101/2021.12.20.21267962; this version posted December 25, 2021. The copyright holder for this

27. Zumbrun, S.D., B. Hoffman, and D.A. Liebermann, Distinct mechanisms are utilized to induce stress sensor gadd45b by different stress stimuli. J Cell Biochem, 2009. 108(5): p. $1220-31$.

28. Liu, C., et al., HILPDA Is a Prognostic Biomarker and Correlates With Macrophage Infiltration in Pan-Cancer. Front Oncol, 2021. 11: p. 597860.

29. Hooikaas, P.J., et al., Kinesin-4 KIF21B limits microtubule growth to allow rapid centrosome polarization in T cells. Elife, 2020.9.

30. Jnana, A., et al., Microbial Community Distribution and Core Microbiome in Successive Wound Grades of Individuals with Diabetic Foot Ulcers. Appl Environ Microbiol, 2020. 86(6).

31. Lavery, L.A., et al., Are We Misdiagnosing Diabetic Foot Osteomyelitis? Is the Gold Standard Gold? J Foot Ankle Surg, 2019. 58(4): p. 713-716.

32. Noor, S., et al., Inflammatory markers as risk factors for infection with multidrugresistant microbes in diabetic foot subjects. The Foot, 2017. 32: p. 44-48.

33. Ismail, A.A., et al., Microbial profile, antimicrobial resistance, and molecular characterization of diabetic foot infections in a university hospital. Germs, 2021. 11(1): p. 39-51.

34. Domínguez-Luis, M., et al., The metalloprotease ADAM8 is associated with and regulates the function of the adhesion receptor PSGL-1 through ERM proteins. Eur J Immunol, 2011. 41(12): p. 3436-42.

35. Grenier, A., et al., Oncostatin M production and regulation by human polymorphonuclear neutrophils. Blood, 1999. 93(4): p. 1413-21. 
medRxiv preprint doi: https://doi.org/10.1101/2021.12.20.21267962; this version posted December 25, 2021. The copyright holder for this preprint (which was not certified by peer review) is the author/funder, who has granted medRxiv a license to display the preprint in perpetuity. All rights reserved. No reuse allowed without permission.

36. Kostylina, G., et al., Neutrophil apoptosis mediated by nicotinic acid receptors (GPR109A). Cell Death \& Differentiation, 2008. 15(1): p. 134-142.

37. Legler, D.F., et al., B cell-attracting chemokine 1, a human CXC chemokine expressed in lymphoid tissues, selectively attracts B lymphocytes via BLR1/CXCR5. The Journal of experimental medicine, 1998. 187(4): p. 655-660.

38. Lipsky, B.A., et al., 2012 Infectious Diseases Society of America clinical practice guideline for the diagnosis and treatment of diabetic foot infections. Clin Infect Dis, 2012. 54(12): p. e132-73.

39. Murray, J.L., et al., Intrinsic Antimicrobial Resistance Determinants in the Superbug Pseudomonas aeruginosa. Mbio, 2015. 6(6).

40. Martin, M., Cutadapt removes adapter sequences from high-throughput sequencing reads. 2011, 2011. 17(1): p. 3.

41. Liao, Y., G.K. Smyth, and W. Shi, featureCounts: an efficient general purpose program for assigning sequence reads to genomic features. Bioinformatics, 2014. 30(7): p. 92330.

42. Mi, H., et al., PANTHER version 16: a revised family classification, tree-based classification tool, enhancer regions and extensive API. Nucleic Acids Res, 2021. 49(D1): p. D394-D403.

43. Pedregosa, F., et al., Scikit-learn: Machine learning in Python. Journal of Machine Learning Research, 2011. 12(Oct): p. 2825--2830. 
medRxiv preprint doi: https://doi.org/10.1101/2021.12.20.21267962; this version posted December 25, 2021. The copyright holder for this preprint (which was not certified by peer review) is the author/funder, who has granted medRxiv a license to display the preprint in perpetuity. All rights reserved. No reuse allowed without permission.
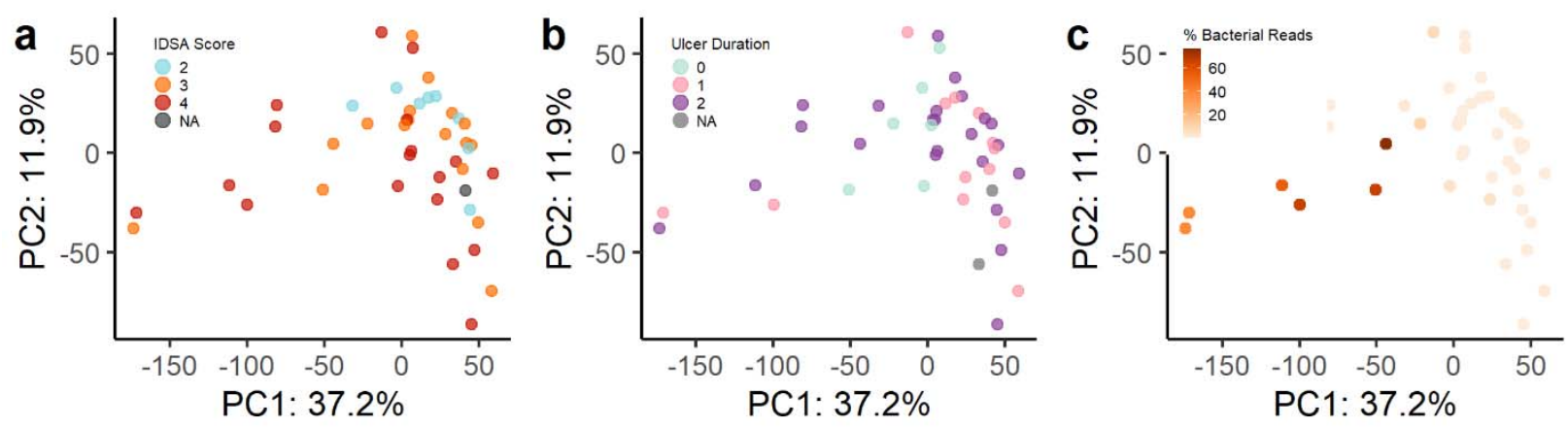

d
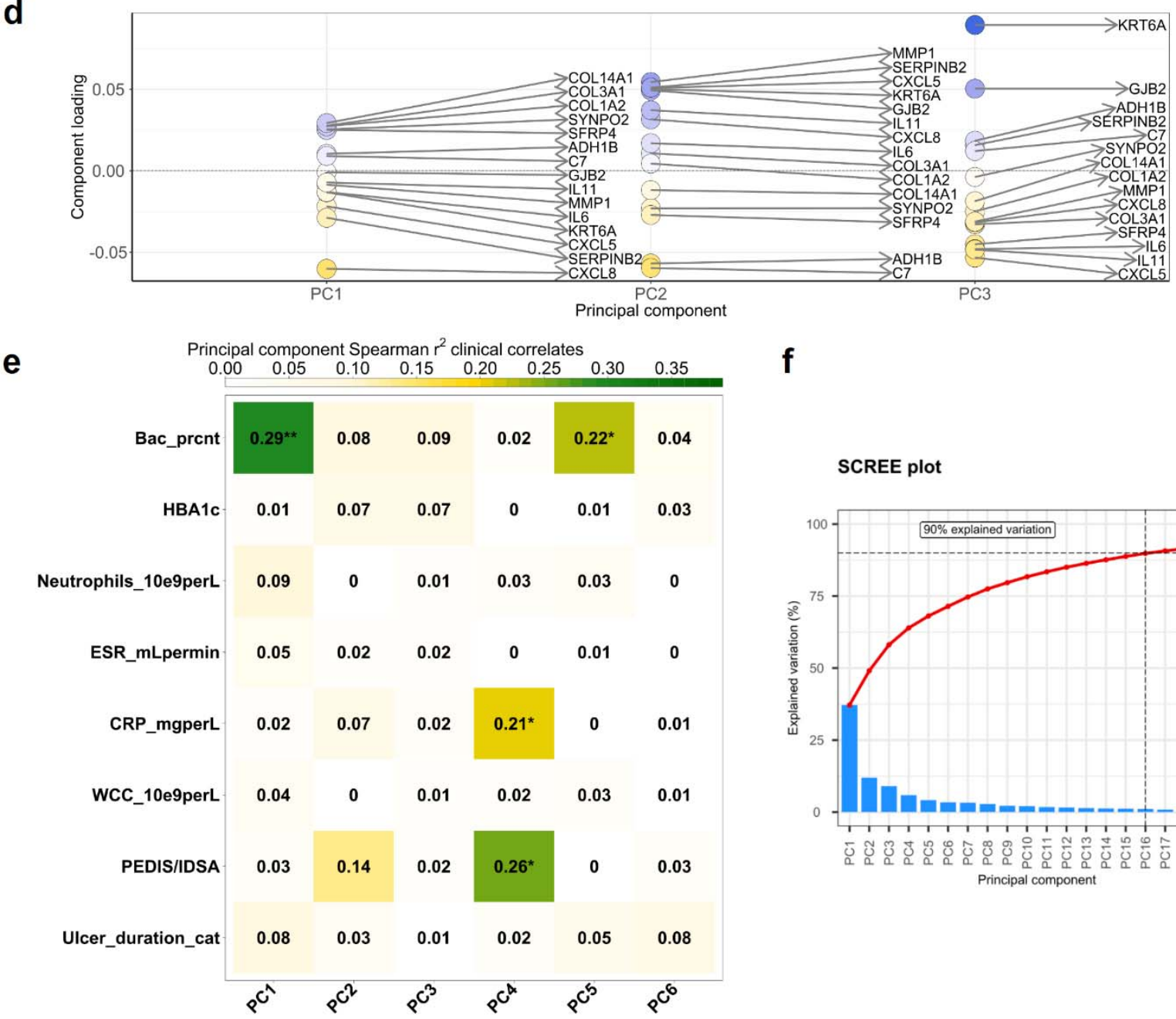

f

SCREE plot

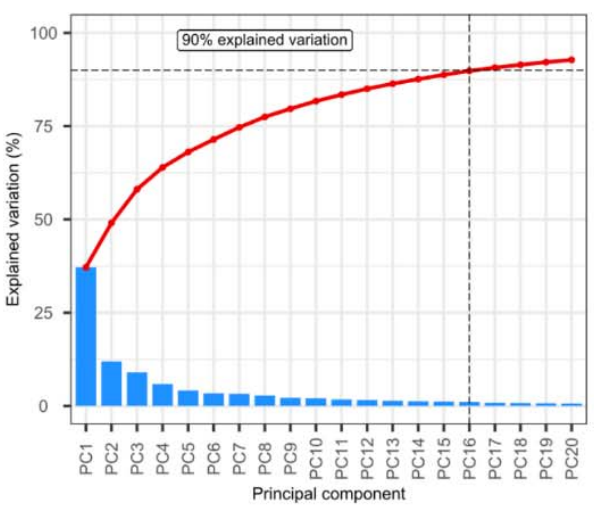


medRxiv preprint doi: https://doi.org/10.1101/2021.12.20.21267962; this version posted December 25, 2021. The copyright holder for this preprint (which was not certified by peer review) is the author/funder, who has granted medRxiv a license to display the preprint in perpetuity. All rights reserved. No reuse allowed without permission.

Figure 1. (a-c) Characterization of host gene expression ulcer transcriptomes $(\mathrm{n}=12,378$ genes) by principal component analysis. Points are colored by: (a) IDSA/PEDIS infection severity score [2:mild, 3:moderate, 4:severe], (b) Ulcer duration [0: less than 2 weeks, 1: 2 to 6 weeks, 2:

Greater than 6 weeks], and (c) Percentage of all RNA-seq reads classified to bacteria. (d) Component loadings for the top 5\% of positive and negatively weighted genes for PC1 to PC3. Points are shaded by component loading value. (e) Spearman correlation coefficients of metadata variables with positioning of a samples along PC1 to PC6. Significance tests were performed with benjamini-hochberg $\mathrm{p}$-value correction for multiple comparisons [**: $\mathrm{p}<0.01,{ }^{*}: \mathrm{p}<0.05$ ]. (f) Scree plot demonstrating the percent of explained variance for PC1 to PC20. The red line represents the cumulative percentage of explained variance across these PCs 
medRxiv preprint doi: https://doi.org/10.1101/2021.12.20.21267962; this version posted December 25, 2021. The copyright holder for this preprint (which was not certified by peer review) is the author/funder, who has granted medRxiv a license to display the preprint in perpetuity.

All rights reserved. No reuse allowed without permission.

a
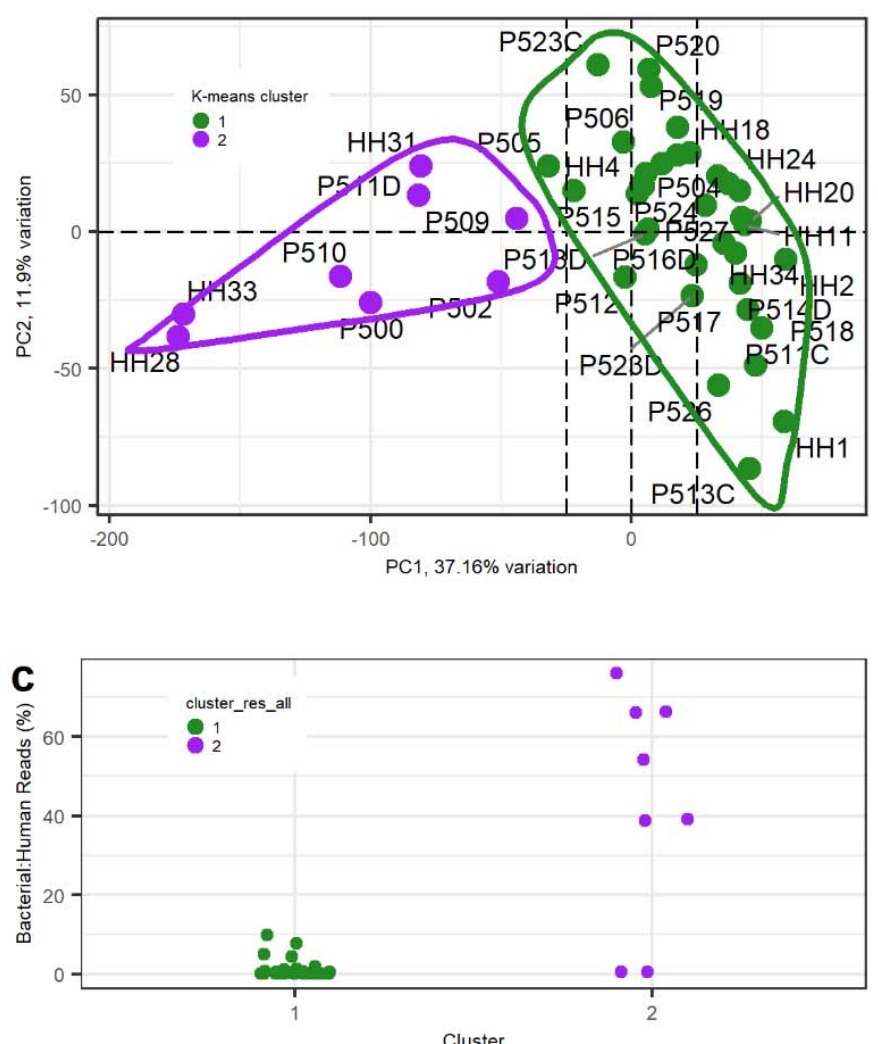

b

\begin{tabular}{|l|l|l|}
\hline GO Term & Fold Enric. & FDR \\
\hline $\begin{array}{l}\text { collagen fibril organization } \\
\text { (GO:0030199) }\end{array}$ & 15.32 & $4.41 \mathrm{e}-06$ \\
\hline $\begin{array}{l}\text { collagen metabolic process } \\
\text { (GO:0032963) }\end{array}$ & 10.00 & $4.91 \mathrm{e}-03$ \\
\hline $\begin{array}{l}\text { complement activation } \\
\text { (GO:0006956) }\end{array}$ & 8.98 & $2.93 \mathrm{e}-02$ \\
\hline $\begin{array}{l}\text { extracellular matrix } \\
\text { organization } \\
\text { (GO:0030198) }\end{array}$ & 7.64 & $3.83 \mathrm{e}-12$ \\
\hline $\begin{array}{l}\text { extracellular structure } \\
\text { organization } \\
\text { (GO:0043062) }\end{array}$ & 7.60 & $2.17 \mathrm{e}-12$ \\
\hline $\begin{array}{l}\text { cellular response to } \\
\text { lipopolysaccharide } \\
\text { (GO:0071222) }\end{array}$ & 2.02 & $4.20 \mathrm{e}-02$ \\
\hline $\begin{array}{l}\text { immune response-regulating } \\
\text { signaling pathway } \\
\text { (GO:0002764) }\end{array}$ & 1.77 & $3.27 \mathrm{e}-02$ \\
\hline $\begin{array}{l}\text { response to molecule of } \\
\text { bacterial origin } \\
\text { (GO:0002237) }\end{array}$ & 1.75 & $3.02 \mathrm{e}-02$ \\
\hline $\begin{array}{l}\text { response to lipopolysaccharide } \\
\text { (GO:0032496) }\end{array}$ & $\begin{array}{l}\text { inflammatory response } \\
\text { (GO:0006954) }\end{array}$ \\
\hline
\end{tabular}

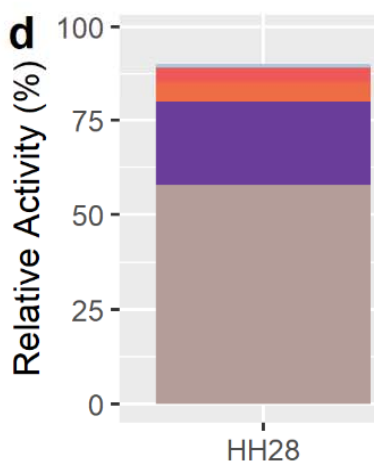

Gemella morbillorum Gudongella oleilytica Pseudomonas aeruginosa Streptococcus australis Alcaligenes faecalis

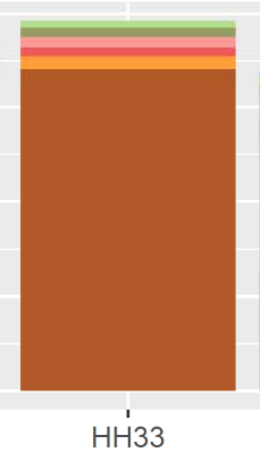

$\mathrm{HH} 33$

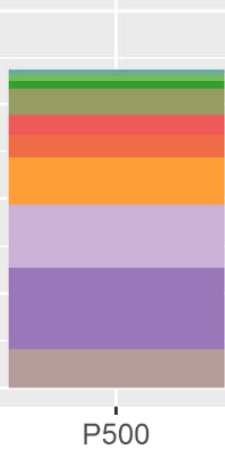

Sample

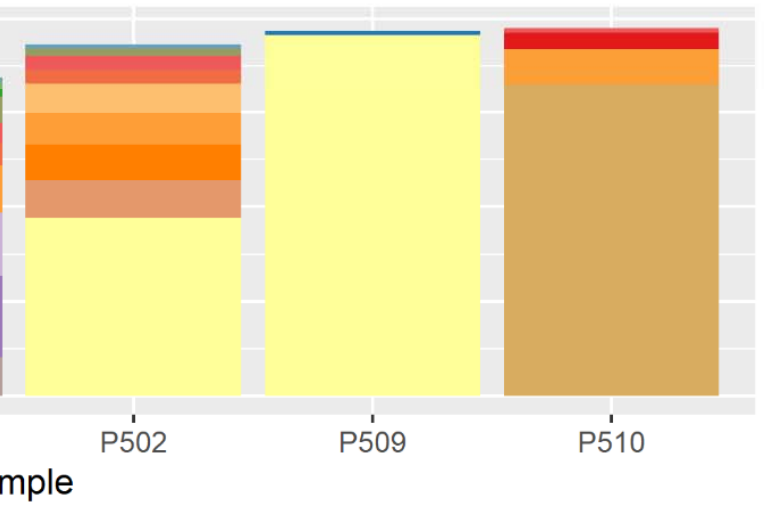

Streptococcus pneumoniae Prevotella jejuni Peptoniphilus hare

Morganella morgani

Anaerococcus prevotii
Enterobacter hormaechei

Anaerococcus mediterraneensis

Peptoniphilus ivorii

Finegoldia magna

Veillonella parvula
Streptococcus agalactiae

Prevotella melaninogenica

Streptococcus oralis

Parvimonas micra

Porphyromonas asaccharolytica
Staphylococcus aureus

Staphylococcus epidermi

Proteus mirabilis 
medRxiv preprint doi: https://doi.org/10.1101/2021.12.20.21267962; this version posted December 25, 2021. The copyright holder for this preprint (which was not certified by peer review) is the author/funder, who has granted medRxiv a license to display the preprint in perpetuity. All rights reserved. No reuse allowed without permission.

Figure 2. (a) Two clusters (C1 and C2) were identified by k-means analysis. Results are displayed projected over the principal component analysis plot of all genes $(n=12,378)$ with points colored by k-means cluster. Samples are labeled by ID, where samples prefixed with "P" and "HH" are from this study and Heravi et al [22], respectively. (b) Gene ontology (GO) terms for GO biological processes showing a significant overrepresentation (Fisher's exact test) of genes identified as differentially expressed between $\mathrm{C} 1$ and $\mathrm{C} 2$. The top 5 overrepresented pathways for cluster 1 (green) and cluster 2 (violet) are shown. (c) Percentage of RNA-seq reads classified to bacteria relative to the total number of reads classified as either bacterial or host for C1 (green) and C2 (purple). The mean percentage of bacterial:human reads was significantly higher in $\mathrm{C} 2(\mathrm{t}=4.04, \mathrm{p}=0.004$, Welch t-test) $(\mathbf{d})$ Relative activity (percentage of RNA reads for a specific species relative to all bacterial reads, \%) for bacterial species with relative activity greater than $1 \%$. Only samples with greater than $10 \%$ bacterial reads are shown. 
medRxiv preprint doi: https://doi.org/10.1101/2021.12.20.21267962; this version posted December 25, 2021. The copyright holder for this preprint (which was not certified by peer review) is the author/funder, who has granted medRxiv a license to display the preprint in perpetuity.

All rights reserved. No reuse allowed without permission.

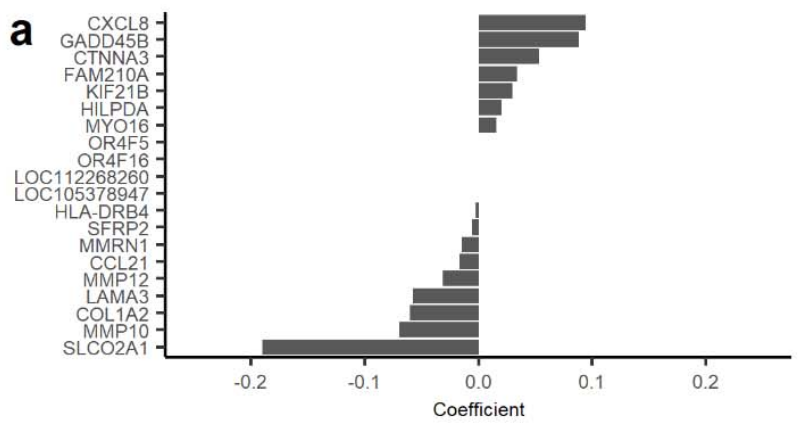

C

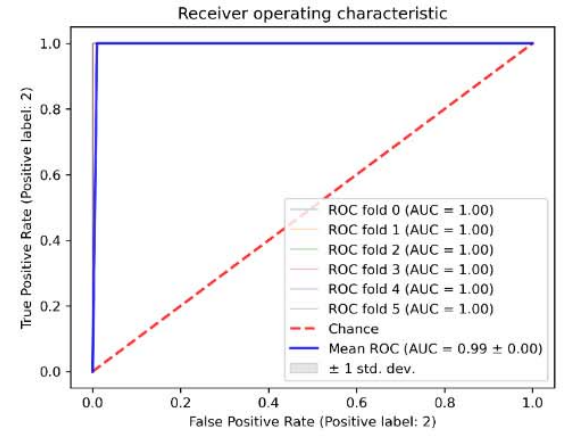

d

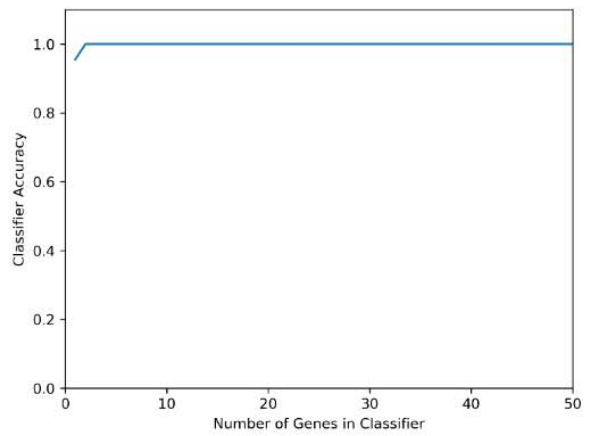

b

\begin{tabular}{|c|c|}
\hline Gene & Product \\
\hline $\mathrm{CCL} 21$ & $\mathrm{C}-\mathrm{C}$ motif chemokine ligand 2 \\
\hline COL1A2 & collagen type I alpha 2 chain \\
\hline CTNNA3 & catenin alpha 3 \\
\hline CXCL8 & $\mathrm{C}-\mathrm{X}-\mathrm{C}$ motif chemokine ligand \\
\hline FAM210A & $\begin{array}{l}\text { family with sequence } \\
\text { similarity } 210 \text { member } A\end{array}$ \\
\hline GADD45B & $\begin{array}{l}\text { growth arrest and DNA damag } \\
\text { inducible beta }\end{array}$ \\
\hline HILPDA & $\begin{array}{l}\text { hypoxia inducible lipid } \\
\text { droplet associated }\end{array}$ \\
\hline HLA-DRB4 & $\begin{array}{l}\text { major histocompatibility } \\
\text { complex }\end{array}$ \\
\hline $\begin{array}{l}\text { KIF21B } \\
\text { LAMA3 }\end{array}$ & $\begin{array}{l}\text { kinesin family member 21B } \\
\text { laminin subunit alpha } 3\end{array}$ \\
\hline LOC10537894 & $\begin{array}{l}\text { proline-rich extensin-like } \\
\text { protein EPR1 }\end{array}$ \\
\hline LOC11226826I & uncharacterized LOC1122682 \\
\hline MMP10 & matrix metallopeptidase 10 \\
\hline MMP12 & matrix metallopeptidase 12 \\
\hline MMRN1 & multimerin 1 \\
\hline MYO16 & myosin XVI \\
\hline OR4F16 & $\begin{array}{l}\text { olfactory receptor family } 4 \\
\text { subfamily } F \text { member } 16\end{array}$ \\
\hline OR4F5 & $\begin{array}{l}\text { olfactory receptor family } 4 \\
\text { subfamily } F \text { member } 5\end{array}$ \\
\hline SFRP2 & $\begin{array}{l}\text { secreted frizzled related } \\
\text { protein } 2\end{array}$ \\
\hline SLCO2A1 & $\begin{array}{l}\text { solute carrier organic anion } \\
\text { transporter family member } 2 \mathrm{~A}\end{array}$ \\
\hline
\end{tabular}
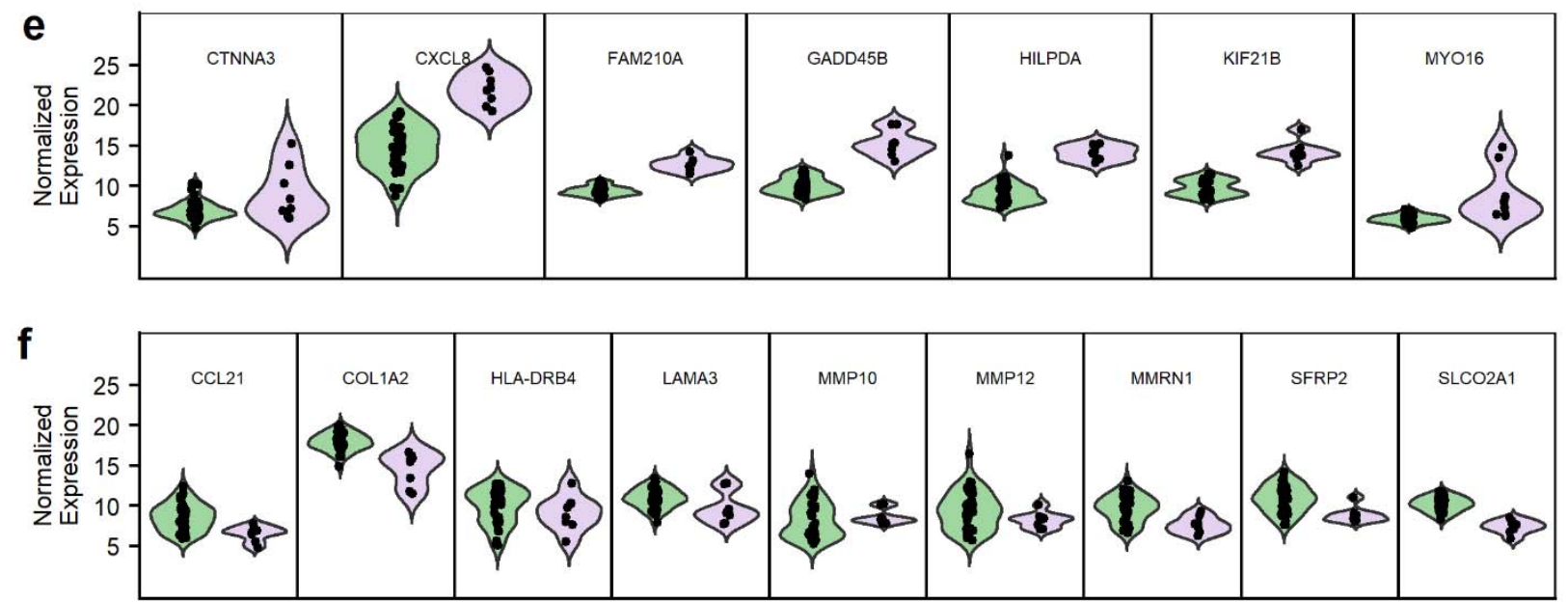
medRxiv preprint doi: https://doi.org/10.1101/2021.12.20.21267962; this version posted December 25, 2021. The copyright holder for this preprint (which was not certified by peer review) is the author/funder, who has granted medRxiv a license to display the preprint in perpetuity. All rights reserved. No reuse allowed without permission.

Figure 3. (a) Coefficient values for the top 20 genes extracted from the support vector classifier. (b) Gene symbols and products for identified features. (c) Receiver operating characteristic curve from cross-validation (6-fold, stratified) analysis. Given the 20 gene fingerprint, the classifier performed with $100 \%$ accuracy for classifying test samples in each fold. (d) Plot of classifier accuracy versus number of features included in the classifier and tested via stratified, 6-fold cross validation for each number of features. 